\title{
From distant collaboration to collaborative presentation: the EdD and one bedtime story more
}

\author{
Poppy Gibson, Suzie Dick \\ University of Greenwich, North Ayrshire Council, University of Glasgow
}

\begin{abstract}
As part of their ever-evolving doctoral journey, the authors presented their recently-published article 'The EdD and one bedtime story more! An exploration of the Third Space inhabited by mothers working in educational leadership whilst studying for a professional doctorate' (Gibson, Shanks and Dick, 2017) at the Greenwich SHIFT Teaching and Learning Conference, 2018.

From distant collaboration to collaborative presentation, the conference brought together two of the three women who had written the article together via online communications between London to Scotland in a virtual 'third space' (Soja, 1999), having never previously met face to face. Third spaces, such as online messenger platforms as used by the authors, can provide a place for individuals to collaborate, and identities to develop. The article focused on the "ever-present pressures, tensions and opportunities for women leaders in education" (Gibson, Shanks and Dick, op.cit., p.172). This conference piece draws parallels between the pressures, tensions and opportunities that conferences can provide. The article offers an opportunity for further reflection on the experience of the conference as yet another part of doctoral study and makes links to the original article's claim that study can be a 'third space' (Soja, op.cit.). The conference revealed itself as the ideal third space for both professional and personal development.
\end{abstract}

Keywords: leadership, women, Doctorate in Education, capabilities, conference

\section{Introduction}

The premise of our original research into doctoral study was to explore the "ever-present pressures, tensions and opportunities for women leaders in education" (Gibson, Shanks and Dick, 2017, p.172) that women leaders in education have to undergo. In this conference reflection piece, these three elements are drawn upon as we consider the experience and how the subject matter of identity and study has been stimulated further through the experience of the Greenwich SHIFT Teaching and Learning Conference, 2018. From distant collaboration to collaborative presentation, the conference offered us - authors who had written the article together via online communications between London and Scotland and without any face-to-face contact - the opportunity, finally, to collaborate in the non-virtual world.

Third spaces (Soja, 1999), such as online messenger platforms as used during our writing of the article, can provide a place for individuals to collaborate and identities to develop. We found that the constant availability and reliable presence of the internet meant we could fit 
communications around our busy family and working lives and we often messaged late into the evening. This behaviour reflects the core message of the original article. The aim of our recently-published article 'The EdD and one bedtime story more! An exploration of the Third space inhabited by mothers working in educational leadership whilst studying for a professional doctorate' (Gibson, Shanks and Dick, 2017) was to analyse links between identity, pursuit of excellence and the pursuit of a complete, worthwhile life through the narratives of three female doctoral students.

\section{Pressures}

Public speaking anxiety (PSA) is the most commonly-experienced type of anxiety (Kumar et al., 2017, p.287), yet conferences are often are often well-attended, with much competition for their presentation opportunities. Indeed, Despite our own multiple concurrent roles as mothers, we chose to submit an abstract for the SHIFT Conference. To our delight, our proposal was accepted and we were offered a slot at the January event. To try to overcome the pressures that are often associated with public speaking and some of the most common nervous habits that manifest themselves on such occasions - filled pauses, tongue clicks and inappropriate use of the word 'like' (Spieler and Miltenberger, 2017, p.38) - we knew that we would need to prepare our talk with audience and purpose clearly in mind.

Additionally, as the title of this piece reflects, we had to consider the fact that though we had written a joint paper, we had never met each other in person; we therefore needed to meet and familiarise ourselves with each other's habits, speech and presentation styles while simultaneously preparing to present. Through social constructionism, we - as two of the three authors - supported and guided each other as we took this next step on our doctoral journey: the step from writers to speakers, each encouraging and giving advice to the other. Prior to the conference, it was also important - considering the transposition of written journal article to verbal reflection - to review our material together and to consider the likely impact of our speech (Slutsky and Baum, 2017) on the audience. As public speaking is associated with fear of negative evaluation and anxiety, it has the potential to undermine self-confidence and self-image (Mehta, 2018, p.81). To overcome the pressures of conference speaking, we found it helpful to focus on what we do well (rather than on weaknesses) as the means of boosting our self-confidence (Mehta, op.cit.).

\section{Tensions}

Tensions that may be felt at a conference may link to Imposter Syndrome (IS). Interestingly, in the 1970s, IS was first considered a trend among women who were advancing professionally (Coombes and Gibson, 2018). The literature shows that sufferers of IS have a 'secret fear' inside them (Qureshi et al., 2017, p.107) and this fear was certainly something tangible when presenting a conference at the institution where one of us worked. For one of the authors, this was her first experience of presenting at a university, with the additional concern of being the imposter within the writing partnership; each author was therefore keen to establish on this first meeting a sense of genuinely equal partnership, both in the writing and the forthcoming presentation. 


\section{Opportunities and conclusion}

Post-session reflections about the actual presentation revealed that it was through confronting the 'imposter' feeling - and refusing to be overwhelmed or commanded by it that self-esteem was in fact reinforced. The main opportunity presented by the SHIFT conference was that of two of the authors finally meeting face to face. Yet it was more than just that; by meeting and presenting together, the authors were taking a step forward in sharing an aspect of their identity and bringing out into the open the people they had previously been, in Soja's third space.

Presenting and surviving the experience showed us that we can take control of situations and that conferences are the ideal way to perform and present research in a safe context. The conference, upon reflection, provided yet another 'third space' for the authors, this one a non-virtual space as opposed to the previously-utilised virtual messaging platform. We reflect that women on doctoral programmes must not give in to the imposter feelings, but instead must live with them and battle through them by availing themselves of the opportunities that are presented by both conferences and publication. By accepting that tensions and pressures are but part of our personal and professional lives, these opportunities, in turn, can lead us further along the path towards a worthwhile life.

\section{Biographical note}

Poppy Gibson is a lecturer in Primary Education in the Teacher Education Department., coming into HE after over a decade working in several London primary schools. Poppy currently works on the University of Greenwich's Accelerated Degree programme in Primary Education and is the Modern Foreign Language coordinator, teaching MFL on the PGCE and BA QTS programmes. Key research interests include identity, motivation and the integration of technology into our lives.

Suzie Dick is a deputy head teacher on the Isle of Arran, Scotland, having previously worked in a number of schools in the UK and abroad. Suzie is currently undertaking her EdD at the University of Glasgow and set up and co-ordinates North Ayrshire Council's Educational Research Interest Group. Her key research interests include outdoor learning, teacher identity and practitioner enquiries.

\section{Reference list}

Coombes, S. and Gibson, P. (2018) 'Feeling like a fraud: Engaging Students with Imposter Syndrome.' Higher Education Journal of Teaching and Learning. Available at: http://hejlt.org/article/feeling-like-a-fraud-engaging-students-with-imposter-syndrome/ (Accessed: 30 July 2018).

Gibson, P., Shanks, R., and Dick, S. (2017) The EdD and One Bedtime Story More! An exploration of the Third Space inhabited by mothers working in educational leadership whilst studying for a professional doctorate. Management in Education, 32 (4). (Accessed: 8 April 2018). 
Kumar, M., Kalakbandi, V., Prashar, S., Neelu, X. and Parashar, A. (2017) 'Overcoming the effect of low self-esteem on public speaking anxiety with mindfulness-based interventions.' Decision (0304-0941), 44(4), 287-296 (Accessed: 30 April 2018).

Qureshi, M., Taj, J., Latif, M., Rafique, S., Ahmed, R. and Chaudhry, M. (2017) 'Imposter Syndrome among Pakistani Medical Students.' Annals of King Edward Medical University, 23(2), 107-111. (Accessed: 30 May 2018).

Shi, X., Brinthaupt, T. and McCree, M. (2017) 'Understanding the Influence of Self-Critical, Self-Managing, and Social-Assessing Self-Talk on Performance Outcomes in a Public Speaking Context.' Imagination, Cognition \& Personality, 36(4), 356-378 (Accessed: 30 April 2018).

Slutsky, J. and Baum, N. (2017) 'Public Speaking for the Podiatric Physician--Part 1: The key to a successful execution is careful planning.' Podiatry Management, 36(8), 87-90 (Accessed: 15 April 2018).

Spieler, C. and Miltenberger, R. (2017) 'Using awareness training to decrease nervous habits during public speaking.' Journal of Applied Behaviour Analysis, 50(1), 38-47. (Accessed: 30 May 2018). 